\title{
Genomic imbalances and $M Y B$ fusion in synchronous bilateral adenoid cystic carcinoma and invasive lobular carcinoma of the breast
}

\author{
ANIKÓ KOVÁCS ${ }^{1}$, FREDRIK PERSSON ${ }^{1,2}$, MARTA PERSSON $^{3}$, \\ MATTIAS K. ANDERSSON ${ }^{3}$ and GÖRAN STENMAN ${ }^{1,3}$

\begin{abstract}
${ }^{1}$ Department of Clinical Pathology and Genetics, Sahlgrenska University Hospital, ${ }^{2}$ Department of Oncology, Sahlgrenska University Hospital and Sahlgrenska Cancer Center, ${ }^{3}$ Department of Pathology and Genetics, Sahlgrenska Cancer Center, Institute of Biomedicine, Sahlgrenska Academy at University of Gothenburg, Gothenburg, Sweden
\end{abstract}

Received May 26, 2017; Accepted July 4, 2017

DOI: $10.3892 / \mathrm{mco} .2017 .1330$

\begin{abstract}
The incidence of synchronous bilateral breast carcinomas (BBCs) has increased with a more frequent use of magnetic resonance imaging screening of the contralateral breast in women with newly diagnosed breast cancer. A total of $30 \%$ of all BBCs occur synchronously. In the present study, we describe a unique case of synchronous BBC in a 59-year-old previously healthy woman with no known family history of breast or ovarian cancer. At the time of diagnosis the patient had an invasive lobular carcinoma (ILC) in the right breast and an adenoid cystic carcinoma (ACC) in the left breast. To the best of our knowledge, this is the first published case of bilateral, simultaneously occurring ACC and ILC of the breast. Genome-wide genomic profiling of the tumors revealed that they had distinctly different genomic imbalances. The ACC had a $5.7 \mathrm{Mb}$ interstitial 6q deletion with a breakpoint located in the 3'-part of $M Y B$, resulting in loss of the last coding exon of $M Y B$ and its $3^{\prime}$-UTR. RT-PCR analysis confirmed that the tumor expressed an ACC-specific $M Y B-N F I B$ fusion transcript. In contrast, the ILC had no rearrangements of $6 \mathrm{q}$ or $M Y B-N F I B$ gene fusion but showed instead gain of 1q21.1-qter, loss of 16q11.2-qter, and 22q12.2-q12.3 as the sole genomic imbalances. Notably, concurrent gains of $1 \mathrm{q}$ and losses of $16 \mathrm{q}$ are characteristic features of ILC. Collectively, our findings indicate that the ACC and ILC had originated independently of each other and
\end{abstract}

Correspondence to: Dr Anikó Kovács, Department of Clinical Pathology and Genetics, Sahlgrenska University Hospital, Gula stråket 8 , SE-413 45 Gothenburg, Sweden

E-mail: aniko.kovacs@vgregion.se

Key words: synchronous bilateral breast carcinoma, adenoid cystic carcinoma, invasive lobular carcinoma, breast cancer, genomic profiling, $M Y B$ that the $M Y B-N F I B$ fusion is a specific biomarker for breast ACC.

\section{Introduction}

The definition of synchronous bilateral breast carcinomas (BBC) varies in the literature. Some investigators regard tumors in both breasts as synchronous if they are diagnosed within an interval of 12 months, whereas others regard them as synchronous if they occur within 6 or 3 months (1-3). From a biological point of view, 12 months is considered the most reasonable time period $(4,5)$. The incidence of synchronous $\mathrm{BBCs}$ has increased with the use of magnetic resonance imaging screening of the contralateral breast in women with newly diagnosed breast cancer (6). A total of $30 \%$ of BBCs occur synchronously, which constitutes $<2 \%$ of all breast cancers (7). Breast cancer patients have a 2- to 6-fold higher risk for developing contralateral breast cancer compared to the risk of developing breast cancer for women in the general population $(8,9)$. Risk factors for BBC include young age, family history (e.g., BRCAl/2 germline mutations), lobular type of cancer, and multicentric tumors (8,10-12).

Before a diagnosis of $\mathrm{BBC}$ can be established, contralateral metastatic spread has to be excluded. Synchronous and metachronous BBC with highly concordant genetic profiles strongly suggest contralateral metastasis (13). On the other hand, presence of a carcinoma in situ component in an invasive cancer suggests a primary tumor. The distinction between BBC and breast-to-breast metastasis is important and forms the basis for the choice of therapy and ultimately also for patient outcome. Recent studies using genome-wide genomic profiling methods have facilitated the molecular characterization of synchronous and metachronous BBCs and have made it possible to rule out whether they are separate tumors or have a common origin. Thus far, available data indicate that the majority of BBC evolve independently and have distinct genotypes $(13,14)$.

In the present study, we describe a unique case of synchronous BBC in a patient with an invasive lobular carcinoma (ILC) of solid type in the right breast and an adenoid cystic carcinoma (ACC) in the left breast. Genomic profiling revealed 
that the tumors had few but distinctly different genomic imbalances and that only the ACC expressed the $M Y B-N F I B$ gene fusion. These observations are consistent with an independent origin of the two tumors.

\section{Case report}

Clinical history. The patient was a 59-year-old previously healthy woman with no known family history of breast or ovarian cancer. In January 2015, she had a routine mammography screening at which bilateral breast tumors were detected. Fine needle aspiration cytology (FNAC) of the right breast lesion confirmed the presence of an adenocarcinoma, whereas the FNAC of the left breast lesion was inconclusive and showed only epithelial atypia. A subsequent core biopsy of the left lesion confirmed the presence of an invasive carcinoma, possibly an ACC. Both tumors were located cranially close to the mamilla. In March 2015, bilateral partial mastectomies were performed combined with bilateral axillary sentinel node biopsies. Both tumors were clinically staged as T2N0M0, anatomic stage/prognostic group IIA. The patient was subsequently subjected to a multi-disciplinary conference for post-operative oncologic adjuvant treatment. She received post-operative, bilateral radiotherapy of the mammary glands with $2.66 \mathrm{~Gy} /$ fraction in 16 fractions, and endocrine treatment with an aromatase inhibitor $(1 \mathrm{mg} /$ day of anastrozole during a 5-year period).

Two years after diagnosis, the patient was relapse-free with no clinical, mammographic or ultra-sound evidence of disease in the mammary glands. In June 2016, FNAC of both breasts revealed normal breast tissues without signs of cancer. The study was approved by the Local Scientific Ethics Committee in Gothenburg (Dnr: 287-15). The requirement for informed consent was waived by the ethical committee since the patient material was stripped from direct subject identifiers.

Histopathological and immunohistochemical findings. Microscopic examination of the 26-mm large lesion in the right breast revealed an ILC of solid type, grade 2 (BRE-score 7: tubulus formation 3, nuclear pleomorphism 3, and mitotic activity 1) (Fig. 1A and B). Immunohistochemically, the tumor was negative for E-cadherin and positive for estrogen (95\%) and progesterone $(80 \%)$ receptors (Fig. 1C and D). The Ki-67 index was $20 \%$ and HercepTest was negative. No metastases were found in the sentinel node from the right axilla.

Microscopic examination of the lesion in the left breast revealed an uncommon type of breast cancer, i.e., an ACC measuring $23 \mathrm{~mm}$ at its largest diameter. Histologically, the tumor was composed of epithelial, basaloid, and myoepithelial cells forming typical tubular and cribriform structures (Fig. 2A and B). Combined Alcian blue-PAS staining showed clear blue-stained mucin in the luminal spaces and there was eosinophilic material in the pseudolumina. Immunohistochemically, the tumor was triple negative (estrogen and progesterone receptors and HercepTest were negative) and had a low Ki-67 proliferation index (10\%). The tumor was positive for E-cadherin, p63 (Fig. 2C), $\alpha$-SMA, CD10, and KIT (CD117) (Fig. 2D). Analysis of the sentinel node from the left axilla showed no signs of metastases.
Genomic profiles of the ACC and ILC. Genome-wide array-based comparative genomic hybridization (arrayCGH) analysis of DNAs isolated from the formalin-fixed paraffin-embedded (FFPE) blocks of the ACC and ILC lesions (containing $>75 \%$ tumor cells) was performed with the Human Genome CGH Microarray 244K oligonucleotide arrays (G4411B; Agilent Technologies, Palo Alto, CA, USA) as previously described $(15,16)$. Data analysis was performed with the Nexus Copy Number software version 8.0 (BioDiscovery Inc., El Segundo, CA, USA). Regions partially or completely covered by a previously reported copy number variation were excluded from the analysis.

ArrayCGH analysis of the ACC revealed a single genomic imbalance, that is a $5.7 \mathrm{Mb}$ deletion in 6q23.2-q24.1. The centromeric breakpoint was located in the 3'-part of the $M Y B$ gene with deletion of the last coding exon of $M Y B$ including the 3'-UTR and flanking sequences (Fig. 3A). The telomeric breakpoint was in an intergenic region in $6 \mathrm{q} 24.1$.

The ILC had also relatively few but different genomic imbalances compared to the ACC. It was characterized by gain of a 104.3 Mb segment in 1q21.1-qter, loss of a $43.8 \mathrm{Mb}$ segment in 16q11.2-qter, and loss of a $4.8 \mathrm{Mb}$ segment in 22q12.2-q12.3 (Fig. 3B). There was no evidence of amplifications or homozygous deletions in any of the tumors.

To further characterize the ACC and ILC genomically, we screened both tumors for expression of the ACC-specific $M Y B-N F I B$ gene fusion $(17,18)$. Reverse transcription polymerase chain reaction (RT-PCR) analysis was conducted on RNAs isolated from the FFPE blocks of both tumors using PCR-primers located in MYB exon 14 and NFIB exons 8a, 8c, and 9 as previously described (19). As shown in Fig. 4, the ACC was strongly positive for the $M Y B-N F I B$ fusion whereas the ILC was negative.

\section{Discussion}

The present study describes a unique case of synchronous $\mathrm{BBC}$ with two histologically different carcinomas. At the time of diagnosis the patient had an ILC in the right breast and an ACC in the left breast. The tumors were detected by routine mammography screening. The histopathological diagnoses of both lesions were unequivocal (Figs. 1 and 2) and there was no evidence of ILC or carcinoma in situ component in the surgical specimen from the left breast. To the best of our knowledge this is the first case of bilateral, simultaneously occurring ACC and ILC of the breast. Morphologically and immunohistochemically, the two tumors showed the typical picture and immunoprofile consistent with the respective histological subtype. Thus, the ILC was estrogen and progesterone receptor positive and E-cadherin negative whereas the ACC was triple negative and strongly positive for KIT.

Genome-wide genomic profiling of the tumors provided additional evidence in support of an independent origin of the BBCs. Thus, the ACC had an interstitial $6 \mathrm{q}$ deletion with a centromeric breakpoint located in the 3'-part of $M Y B$, resulting in loss of the last coding exon of $M Y B$ including its 3'-UTR. The deletion, which spanned a 5.7 Mb segment in 6q23.2-q24.1, was the sole genomic imbalance. Previous findings have unequivocally shown that rearrangements of $M Y B$ is the main genomic hallmark of ACC $(15,17,18,20,21)$. The most common $M Y B$ 


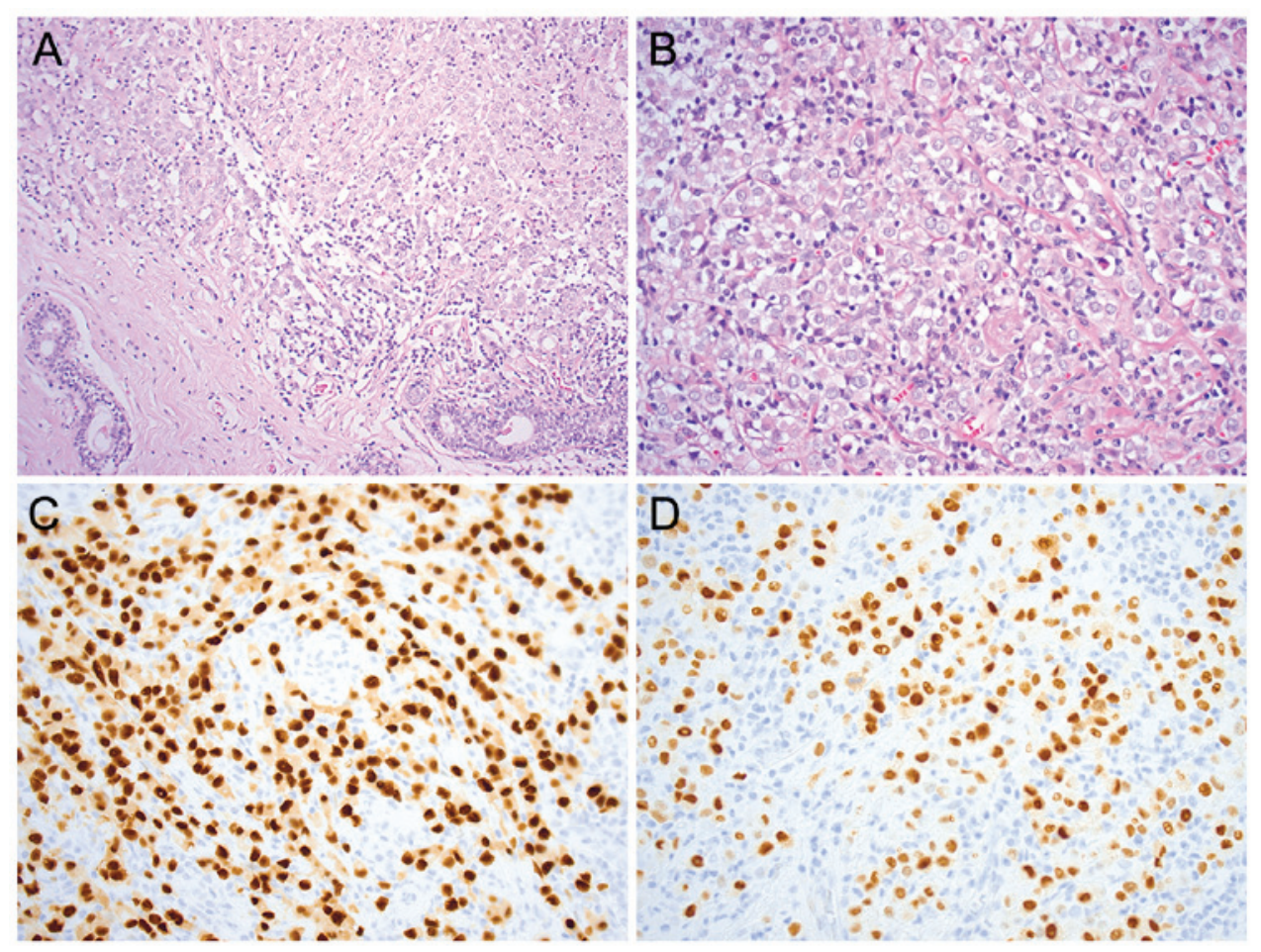

Figure 1. (A and B) ILC of solid type with cords forming sheets of tumor cells, with focal lymphocytic infiltration (H\&E staining; original magnification, $\mathrm{x} 100$ and $\mathrm{x} 200$, respectively). (C and D) The tumor cells are diffusely positive for estrogen (C) and progesterone (D) receptors (original magnification, x200). ILC, invasive lobular carcinoma.
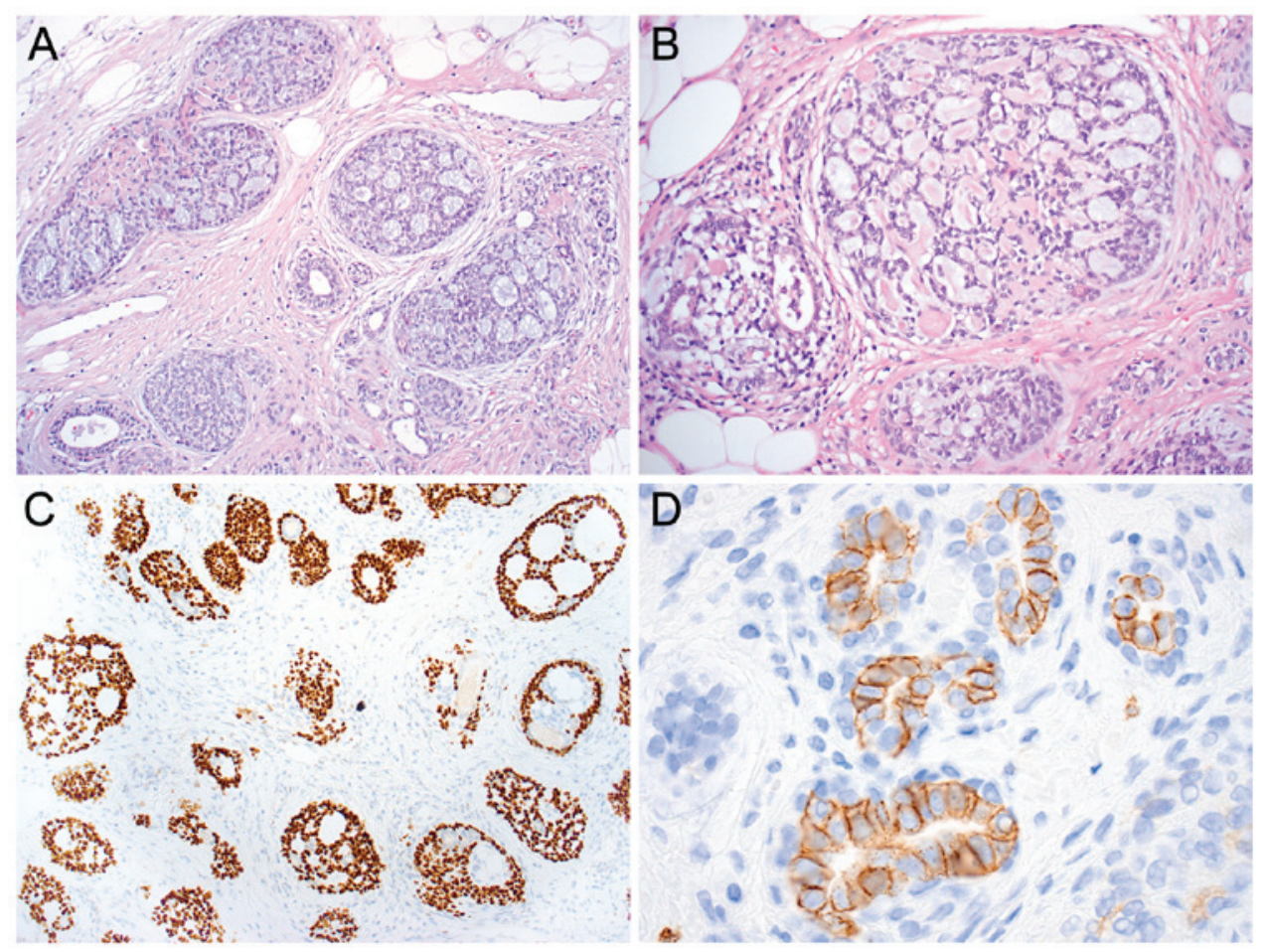

Figure 2. (A and B) ACC with characteristic cribriform structures and well-defined round spaces containing basophilic material (H\&E staining; original magnification, x100 and x200, respectively). (C) Positive nuclear immunostaining for p63 (myoepithelial marker; original magnification, x200). (D) Membrane staining of the KIT oncoprotein (original magnification, $\mathrm{x} 400$ ). ACC, adenoid cystic carcinoma.

alteration in ACC is a $M Y B-N F I B$ gene fusion generated by a $\mathrm{t}(6 ; 9)$ translocation $(22,23)$. In the resulting fusion gene, the 3'-part of $M Y B$ is replaced by the 3'-part of $N F I B$ leading to the overexpression of $M Y B(17,18)$. Activation of $M Y B$ through gene fusion or juxtaposition of strong enhancer elements to $M Y B$ occurs in $80-90 \%$ of ACCs $(18,24,25)$ irrespective of anatomical localization (salivary gland, breast, skin, lacrimal gland, tracheobronchial tree, digestive tract, prostate, and 


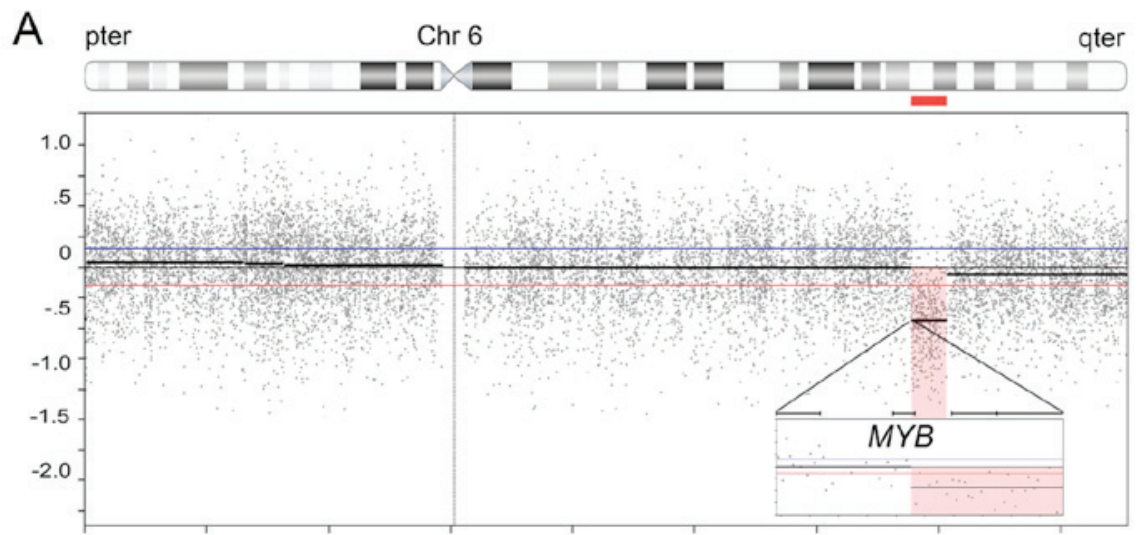

B

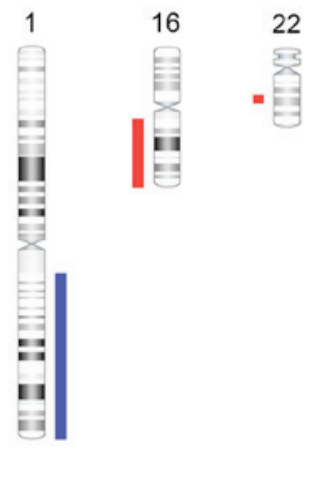

Figure 3. Genomic imbalances in synchronous BBC. (A) ArrayCGH analysis of the breast ACC demonstrating segmental loss of a $5.7 \mathrm{Mb}$ fragment in 6q23.2-q24.1 including the 3'-part of the MYB gene and its 3'-UTR (horizontal red line). (B) Copy number alterations in the ILC, including gain of 1q21.1-qter (vertical blue line) losses of 16q11.2-qter and 22q12.2-q12.3 (red vertical lines). BBC, bilateral breast carcinomas; arrayCGH, array-based comparative genomic hybridization; ACC, adenoid cystic carcinoma; ILC, invasive lobular carcinoma.

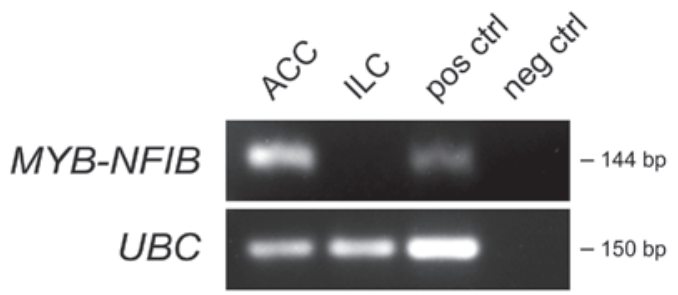

Figure 4. Expression of the $M Y B-N F I B$ gene fusion in synchronous BBC. RT-PCR analysis revealed expression of a 144-bp fragment in the breast ACC corresponding to a chimeric $M Y B-N F I B$ transcript in which exon 14 of $M Y B$ is linked to exon 9 of $N F I B$. The ILC did not express the $M Y B-N F I B$ fusion. A known fusion-positive salivary gland ACC was used as a pos ctrl. Neg ctrl indicates a negative control PCR reaction with gene-specific primers but without cDNA template. $U B C$ was used as a reference gene. The sizes (bp) of the amplified fragments are indicated to the right. $\mathrm{BBC}$, bilateral breast carcinomas; RT-PCR, reverse transcription polymerase chain reaction; ACC, adenoid cystic carcinoma; ILC, invasive lobular carcinoma; pos ctrl, positive control.

female genital tract) $(17,18,26,27)$. In the breast, $>90 \%$ of ACCs have $M Y B$ activation $(21,27)$. In keeping with this observation the present $\mathrm{ACC}$ was also strongly positive for the $M Y B-N F I B$ fusion (Fig. 4). The ubiquitously expressed gene $U B C$ was used as a positive control for the PCR reaction.

In contrast to head and neck ACCs, breast ACCs are usually low-grade tumors with an indolent clinical course. A major reason for this difference is that breast ACCs have very few, if any, genomic alterations other than $M Y B$ rearrangements/activation (as identified in the present case), whereas head and neck ACCs have a much higher frequency of genomic imbalances some of which are associated with an aggressive clinical behavior and a poor prognosis $(15,27)$. However, studies of the mutational landscape of breast and salivary gland ACCs have revealed a similar mutational profile with mutations targeting chromatin remodelling, cell adhesion, RNA biology, ubiquitination, and canonical signaling pathway genes $(20,21,28)$. Furthermore, breast and salivary ACCs show very similar histologies with luminal, basaloid, and myoepithelial cells arranged in tubular and cribriform structures with or without the presence of solid structures (29-31).

ArrayCGH analysis of the present ILC revealed a genomic profile that was completely different from that of the breast
ACC. The ILC had no rearrangements of $6 \mathrm{q}$, did not express the $M Y B-N F I B$ gene fusion, and showed gain of 1q21.1-qter, loss of 16q11.2-qter, and 22q12.2-q12.3 as the sole genomic imbalances. Notably, concurrent gains of $1 \mathrm{q}$ and losses of $16 \mathrm{q}$ are recurrent alterations in ILC (32-34). Taken together, our studies clearly demonstrate that the synchronous BBCs had different histopathologic and genomic characteristics and had developed independently of each other consistent with the classical molecular pathways known for sporadic ACC and ILC (18,34,35).

Previous findings have shown that synchronous BBCs are often of the same histological type and show an association between hormone receptor status and tumor grade $(1,4)$. Despite these similarities, synchronous BBCs are commonly considered as two separate primary tumors evolving in a similar microenvironment and with the same genetic background $(13,14,36,37)$. Notably, there are a number of cases on record with histologically different synchronous bilateral breast tumors. Thus, there is a rare case of pleomorphic adenoma of the breast and a synchronous invasive ductal breast carcinoma in a 58-year-old woman (38). Da Silva et al have also described an interesting case of ACC with synchronous tubular adenosis (39). Although the two tumors occurred in the same breast, genomic analysis indicated that they had an independent origin. The fact that synchronous BBCs are not always identical tumors suggests that they ideally should be treated individually in line with the concept of personalized cancer medicine.

In summary, we describe a unique case of synchronous $\mathrm{BBC}$ in a woman with an ACC in the left breast and an ILC in the right breast. Molecular analyses revealed that the two tumors had different genomic profiles and that the ACC expressed the tumor-type specific $M Y B-N F I B$ gene fusion. Taken together, our findings strongly indicate that the two tumors had originated independently of each other and that the $M Y B-N F I B$ fusion is a specific biomarker for breast ACC.

\section{Acknowledgements}

The present study was supported by the Swedish Cancer Society, and BioCARE, a National Strategic Cancer Research Program at the University of Gothenburg. 


\section{References}

1. Hungness ES, Safa M, Shaughnessy EA, Aron BS, Gazder PA Hawkins HH, Lower EE, Seeskin C, Yassin RS and Hasselgren PO: Bilateral synchronous breast cancer: Mode of detection and comparison of histologic features between the 2 breasts. Surgery 128: 702-707, 2000

2. Hartman M, Czene K, Reilly M, Adolfsson J, Bergh J, Adami H-O, Dickman PW and Hall P: Incidence and prognosis of synchronous and metachronous bilateral breast cancer. J Clin Oncol 25: 4210-4216, 2007.

3. MacGrogan G, Tot T, Rakha E and Morrow M: Bilateral breast carcinoma and nonsynchronous breast carcinoma. In: WHO Classification of Tumours of the Breast. Lakhani SR, Ellis OI, Schnitt SJ, Tan PH and van de Vijver MJ (eds). Vol 4. 4th edition. IARC, Lyon, pp69-70, 2012.

4. Huo D, Melkonian S, Rathouz PJ, Khramtsov A and Olopade OI: Concordance in histological and biological parameters between first and second primary breast cancers. Cancer 117: 907-915, 2011.

5. Holm M, Tjønneland A, Balslev E and Kroman N: Prognosis of synchronous bilateral breast cancer: A review and meta-analysis of observational studies. Breast Cancer Res Treat 146: 461-475, 2014

6. Brennan ME, Houssami N, Lord S, Macaskill P, Irwig L, Dixon JM, Warren RM and Ciatto S: Magnetic resonance imaging screening of the contralateral breast in women with newly diagnosed breast cancer: Systematic review and meta-analysis of incremental cancer detection and impact on surgical management. J Clin Oncol 27: 5640-5649, 2009.

7. Senkus E, Szade J, Pieczyńska B, Zaczek A, Pikiel J, SosińskaMielcarek K, Karpińska A and Jassem J: Are synchronous and metachronous bilateral breast cancers different? An immunohistochemical analysis aimed at intrinsic tumor phenotype. Int J Clin Exp Pathol 7: 353-363, 2013.

8. Chen Y, Thompson W, Semenciw R and Mao Y: Epidemiology of contralateral breast cancer. Cancer Epidemiol Biomarkers Prev 8: 855-861, 1999.

9. Singletary SE: Rating the risk factors for breast cancer. Ann Surg 237: 474-482, 2003.

10. Adami H-O, Hansen J, Jung B and Rimsten A: Characteristics of familial breast cancer in Sweden: Absence of relation to age and unilateral versus bilateral disease. Cancer 48: 1688-1695, 1981.

11. Polednak AP: Bilateral synchronous breast cancer: A population-based study of characteristics, method of detection, and survival. Surgery 133: 383-389, 2003.

12. Jobsen JJ, van der Palen J, Ong F, Riemersma S and Struikmans H: Bilateral breast cancer, synchronous and metachronous; differences and outcome. Breast Cancer Res Treat 153: 277-283, 2015.

13. Song F, Li X, Song F, Zhao Y, Li H, Zheng H, Gao Z, Wang J, Zhang $\mathrm{W}$ and Chen $\mathrm{K}$ : Comparative genomic analysis reveals bilateral breast cancers are genetically independent. Oncotarget 6 . 31820-31829, 2015.

14. Fountzilas E, Kotoula V,Zagouri F, Giannoulatou E, Kouvatseas G, Pentheroudakis G, Koletsa T, Bobos M, Papadopoulou K, Samantas E, et al: Disease evolution and heterogeneity in bilateral breast cancer. Am J Cancer Res 6: 2611-2630, 2016.

15. Persson M, Andrén Y, Moskaluk CA, Frierson HF Jr, Cooke SL, Futreal PA, Kling T, Nelander S, Nordkvist A, Persson F and Stenman G: Clinically significant copy number alterations and complex rearrangements of $M Y B$ and $N F I B$ in head and neck adenoid cystic carcinoma. Genes Chromosomes Cancer 51 805-817, 2012.

16. Jee KJ, Persson M, Heikinheimo K, Passador-Santos F, Aro K, Knuutila S, Odell EW, Mäkitie A, Sundelin K, Stenman G and Leivo I: Genomic profiles and CRTC1-MAML2 fusion distinguish different subtypes of mucoepidermoid carcinoma. Mod Pathol 26: 213-222, 2013.

17. Persson M, Andrén Y, Mark J, Horlings HM, Persson F and Stenman G: Recurrent fusion of $M Y B$ and $N F I B$ transcription factor genes in carcinomas of the breast and head and neck. Proc Natl Acad Sci USA 106: 18740-18744, 2009

18. Andersson MK and Stenman G: The landscape of gene fusions and somatic mutations in salivary gland neoplasms - Implications for diagnosis and therapy. Oral Oncol 57: 63-69, 2016.

19. Fehr A, Kovács A, Löning T, Frierson H Jr, van den Oord J and Stenman G: The $M Y B-N F I B$ gene fusion-a novel genetic link between adenoid cystic carcinoma and dermal cylindroma. J Pathol 224: 322-327, 2011

20. Ho AS, Kannan K, Roy DM, Morris LG, Ganly I, Katabi N Ramaswami D, Walsh LA, Eng S, Huse JT, et al: The mutational landscape of adenoid cystic carcinoma. Nat Genet 45: 791-798, 2013.
21. Martelotto LG, De Filippo MR, Ng CK, Natrajan R, Fuhrmann L, Cyrta J, Piscuoglio S, Wen HC, Lim RS, Shen R, et al: Genomic landscape of adenoid cystic carcinoma of the breast. J Pathol 237: 179-189, 2015.

22. Stenman G, Sandros J, Dahlenfors R, Juberg-Ode M and Mark J: 6q- and loss of the Y chromosome - two common deviations in malignant human salivary gland tumors. Cancer Genet Cytogenet 22: 283-293, 1986.

23. Nordkvist A, Mark J, Gustafsson H, Bang G and Stenman G: Non-random chromosome rearrangements in adenoid cystic carcinoma of the salivary glands. Genes Chromosomes Cancer 10: 115-121, 1994.

24. Brayer KJ, Frerich CA, Kang H and Ness SA: Recurrent fusions in $M Y B$ and $M Y B L 1$ define a common, transcription factor-driven oncogenic pathway in salivary gland adenoid cystic carcinoma. Cancer Discov 6: 176-187, 2016.

25. Drier Y, Cotton MJ, Williamson KE, Gillespie SM, Ryan RJ, Kluk MJ, Carey CD, Rodig SJ, Sholl LM, Afrogheh AH, et al: An oncogenic MYB feedback loop drives alternate cell fates in adenoid cystic carcinoma. Nat Genet 48: 265-272, 2016.

26. Brill LB II, Kanner WA, Fehr A, Andrén Y, Moskaluk CA, Löning T, Stenman G and Frierson HF Jr: Analysis of MYB expression and $M Y B-N F I B$ gene fusions in adenoid cystic carcinoma and other salivary neoplasms. Mod Pathol 24: 1169-1176, 2011.

27. Wetterskog D, Lopez-Garcia MA, Lambros MB, A'Hern R, Geyer FC, Milanezi F, Cabral MC, Natrajan R, Gauthier A, Shiu K, et al: Adenoid cystic carcinomas constitute a genomically distinct subgroup of triple-negative and basal-like breast cancers J Pathol 226: 84-96, 2012.

28. Wetterskog D, Wilkerson PM, Rodrigues DN, Lambros MB, Fritchie K, Andersson MK, Natrajan R, Gauthier A, Di Palma S, Shousha $\mathrm{S}$, et al: Mutation profiling of adenoid cystic carcinomas from multiple anatomical sites identifies mutations in the RAS pathway, but no KIT mutations. Histopathology 62: 543-550, 2013.

29. Sapino A, Sneige N and Eusebi V: Adenoid cystic carcinoma. In: WHO Classification of Tumours of the Breast. Lakhani SR, Ellis OI, Schnitt SJ, Tan PH and van de Vijver MJ (eds). Vol 4. 4th edition. IARC, Lyon, pp56-57, 2012.

30. Foschini MP, Morandi L, Asioli S, Giove G, Corradini AG and Eusebi V: The morphological spectrum of salivary gland type tumours of the breast. Pathology 49: 215-227, 2017.

31. Stenman G, Licitra L, Said-Al-Naief N, van Zante A and Yarbrough WG: Adenoid cystic carcinoma. In: WHO Classification of Head and Neck Tumours. Vol 9. 4th edition. El-Naggar AK, Chan JKC, Grandis JR, Takata T and Slootweg PJ (eds). IARC, Lyon, pp164-165, 2017.

32. Hungermann D, Schmidt H, Natrajan R, Tidow N, Poos K, Reis-Filho JS, Brandt B, Buerger H and Korsching E: Influence of whole arm loss of chromosome $16 \mathrm{q}$ on gene expression patterns in oestrogen receptor-positive, invasive breast cancer. J Pathol 224: 517-528, 2011.

33. Stacher E, Boldt V, Leibl S, Halbwedl I, Popper HH, Ullmann R, Tavassoli FA and Moinfar F: Chromosomal aberrations as detected by array comparative genomic hybridization in early low-grade intraepithelial neoplasias of the breast. Histopathology 59: 549-555, 2011.

34. Lakhani SR, Rakha E and Simpson PT: WHO Classification of Tumours of the Breast. Lakhani SR, Ellis OI, Schnitt SJ, Tan PH and van de Vijver MJ (eds). Vol 4. 4th edition. IARC, Lyon, pp40-42, 2012.

35. Stenman G, Andersson MK and Andrén Y: New tricks from an old oncogene: Gene fusion and copy number alterations of $M Y B$ in human cancer. Cell Cycle 9: 2986-2995, 2010.

36. Tse GMK, Kung FYL, Chan ABW, Law BKB, Chang AR and Lo K-W: Clonal analysis of bilateral mammary carcinomas by clinical evaluation and partial allelotyping. Am J Clin Pathol 120: 168-174, 2003.

37. Saad RS, Denning KL, Finkelstein SD, Liu Y, Pereira TC, Lin X and Silverman JF: Diagnostic and prognostic utility of molecular markers in synchronous bilateral breast carcinoma. Mod Pathol 21: 1200-1207, 2008.

38. Di Bonito M, Cantile M, Cerrone M, Liguori G and Botti G: Synchronous pleomorphic adenoma and invasive ductal carcinoma in distinct breasts. Breast J 21: 428-430, 2015.

39. Da Silva L, Buck L, Simpson PT, Reid L, McCallum N, Madigan BJ and Lakhani SR: Molecular and morphological analysis of adenoid cystic carcinoma of the breast with synchronous tubular adenosis. Virchows Arch 454: 107-114, 2009. 